\title{
Research on the Ways of Economic Transformation in YuLin under the New Normal
}

\author{
Di Zhang, a * \\ ${ }^{1}$ School of Management, Yulin University, China, 719000 \\ a76969980@qq.com
}

Keywords: Economic; Yulin; Transformation; The New Normal

\begin{abstract}
The economic of Yulin has bid farewell to the era of rapid development, has entered a new norm, The economic of Yulin must be changed. Based in Yulin is the rapid economic development in backward areas the situation judgment, analyze the deep reason of the extensive economic development in Yulin, explore the transformation path of economic development in Yulin under the new economic norm: change the concept of development is the basic premise. Promote energy industry high-end is the only way which must be passed, vigorously develop new industries is the necessary means to speed up the adjustment of industrial structure is the fundamental measure to enhance scientific and technological innovation ability is the key link. Introduction.
\end{abstract}

\section{Introduction}

In May 2014, Chinese President Xi Jinping pointed out in the Henan, China's development is still in an important period of strategic opportunities, we must strengthen confidence, starting from the current features of China's development, to adapt to the new normal, maintain a normal state of mind on the strategy. In the new norm to summarize the new features of the current Chinese economy, and the up to the strategic level, shows that the Party Central Committee with Comrade Xi Jinping as general secretary of the understanding of the current stage of economic growth China changes more deeply. The new normal in a relatively stable state, that China economy has entered a new stage of rapid growth in the past 30 years of economic growth speed, economic transformation comprehensive upgrade, economic structure, profound changes, to continue upgrading. As a typical resource type city, Yulin economy also suffered cold but hitherto unknown, Fundamentals of the Yulin city economy development has not changed, orientation of national energy and chemical base did not change, an important part of Shaanxi's economic status has not changed. In order to adapt and develop under the new economic normal, we must optimize the economic development of Yulin, explore the transformation path of economic development.

\section{The Current Development of Yulin's Economy under The New Normal}

The Speed of Economic Growth is Still Faster in YuLin. The GDP was 2773.05 million yuan of YuLin in 2016, which growth $6.5 \%$ over the previous year. Among them, The first industrial added value of 162.44 million yuan, an increase of $4.8 \%$; The second of the industrial added value of 168 0.70 million yuan, an increase of $4.1 \%$; The third of the industrial added value of 929.91 million yuan, an increase of $11.1 \%$. The three industrial added value accounted for the proportion of GDP was $5.9 \%, 60.6 \%$ and $33.5 \%$. Yulin in the past 5 years, the total economy is increasing year by year, but the growth rate has been declining, but the overall growth rate is still faster. The proportion of the second industry is still the largest in the main position.

The Development of Economic and Social Inharmonious. Although Yulin in education, employment, medical care, subsistence allowances, pension and other livelihood improvement in the overall progress, but is still showing a long leg and a short "situation. In: infrastructure more loans, housing, transportation, cultural and other public service system construction lag; high technology talents shortage, innovation platform number research and the ability to keep up with the demand of economic development, the overall technology transfer rate is only $45 \%$; the uneven distribution of educational resources in city, although the implementation of sunshine admissions 
policies, the implementation of balanced placement system, principal teacher exchange rotation system, in the" choice "has improved, but the layout adjustment of rural schools has brought new schooling" your doctor "; the problem is still not solved fundamentally, the differences between urban and rural medical resources and the level of lead in township hospital no patient, hospital, hospital and city hospital overcrowding.

The Imbalance of Economic Development. The so-called imbalance refers to two aspects: from the perspective of regional imbalance, less than $8 \%$ of the six counties in southern Yulin in the city of GDP, per capita GDP of the city's level of $27 \%$, local fiscal revenue accounted for $1.59 \%$. Yulin income of million Township almost all concentrated in the north of the six county (District), the income of over 10000 yuan Village South six counties accounted for only about 1/7; the South and North in the development of private enterprises on a larger gap, the South accounted for only 2. From the industry level, the development level of some industries in Yulin as a world class, now the world's most advanced coal chemical technology in Yulin can see. But some very backward six, the rural economy of South County is still in the traditional state of peasant economy, economic growth is mainly rely on land and labor and other ancient production factors for support, but rural economic growth in northern industrial driven economy, with capital, technology for mineral, these factors of production Main support

The Economic Development is not Sustainable. Unsustainable development refers to the potential risk of economic development: the first is the capacity of the ecological environment in Yulin challenge. With the rapid development of mineral resources, coal mining, high energy consumption, coal and coal chemical industries such as high pollution and high emissions to form great risks for the limited capacity of the ecological environment of Yulin is a severe water shortage area. In 2015, 340 million cubic meters of water, in 2020 will reach 700 million cubic meters. The industrial structure of Yulin's existing industrial layout is to determine the coal chemical industry, salt chemical industry, coal and other industries, these industries are high energy consuming industries, and high water consumption industries. The number of lakes large scale development is reduced by $90 \%$, Hongjiannao water per year drop a few centimeters. The current king shagedu reservoir capacity of 390 million cubic meters, although can give Yu Wang Industrial Area of water supply, but the future of Shenfu coal chemical project to bring water from the Yellow River coal mine, Shu dried Water comprehensive utilization technology still needs to be improved; due to mining of the mined out area is about 550 square kilometers, the collapse area of about 130 square kilometers. The collapse of the earthquake prone, some gob surface subsidence has reached 2 meters. Secondly, the ability of independent innovation of Yulin. Yulin is a cultural taste is not high the city of Yulin science and technology. The conversion rate is only $45 \%$, with strong dependence on foreign technology, high-end technical talents, especially some practical technology and talent is scarce seriously. Don't say that the city of Suzhou and Shenzhen, are not comparable, even with the brothers in Baoji City, Weinan is also a big difference.

\section{The Causes of the Extensive Mode of Economic Development in Yulin}

The Inevitable Result of Domestic and Foreign Industrial Transfer. China is a coal less oil and gas, foreign energy dependence has reached 57\%. in global energy consumption structure, carbon based energy in the total energy in the proportion is as high as $87 \%$. plus the world economy depth adjustment, large-scale industrial transfer in eastern China, a lot of labor intensive industries. Resource-based industries shift to the west, the domestic and foreign huge energy demand and the industrial transfer at home and abroad is the power and source of Yulin economy more than 10 years of rapid growth.

The Product of Primary Stage on Development of Resource-based City. Common resources city is the primary stage of development: economic development mainly to resource development, the development of diversification, enterprises seek to maximize the interests of the government to pursue the maximization of GDP. Due to over reliance on resources, the transformation is not in place at the same time, resource depletion of "resource curse" (also known as Dutch disease) arrived. The "resource curse" it is dangerous to the economic development of a country or region for some 
rich resources. Over reliance on resources industry in the expansion period of prosperity tend to other industries at the expense of the crowding out effect on other industries, when the boom ended, the collapse of economic growth. This is a common problem in the early stage of development of resource type city the Yulin is the only disease in early stage, because of Yulin's resources is not exhausted. If the exhaustion of resources, the current mode of development and industrial structure, it is regarded as hopeless.

The Economic Development of China has Entered a New Norm. The new economic norm is characterized in high speed, the rapid growth of economic growth from the rapid growth of about $10 \%$ in the past into $7 \%---8 \%$; excellent structure, the third industry has gradually become the main industry, consumer demand has gradually become the main demand, and gradually narrow the gap between urban and rural areas, the proportion of residents' income rise; new power, economic development will be driven from the elements, investment driven to innovation driven; many challenges, some uncertainty risk dominance, such as market risk, the risk of local debt, the potential risks of financial risk gradually surfaced. The primary feature of the new norm is the decline in economic growth, for Yulin is a resource-based city, influence is enormous.

\section{The Transformation Path of Economic Development in Yulin}

The Basic Premise is to Change the Concept of Development. The economy of Yulin and the national synchronized into the rapid growth to shift to high growth period, do not expect Yulin's economy to go back to the "running" state, to realize the speed of economic development "an unsettled state of mind." will become a kind of normal. GDP must maintain a certain speed, but also not only GDP, as general secretary Xi Jinping said: "we are no longer simply to GDP growth heroes, but stressed that in order to improve the quality and efficiency of economic growth as a foothold." don't hate to shovel coal dug out to sell, wait a spoon to scoop out oil are sold. Stay in there black charcoal, must be transformed into relying on energy, but can not rely on energy development ideas, accelerate the transformation of development mode, and strive to build an upgraded version of Yulin economy.

The Only Way is to Promote the High-end of energy industry. Yulin is a major producer of traditional coal chemical products, such as coke, ammonia, calcium carbide and other products now have varying degrees of overcapacity. Modern coal chemical products such as coal oil, coal gas, coal to olefins fine coal chemical products can replace petroleum products. From the traditional upgrade to a modern coal chemical industry, have a positive role to protect China's energy security and build an upgraded version of Yulin economy. Of course in the process of industrial upgrading needs to overcome many difficulties, for example, requires a large amount of capital, a lot of technology, such as coal oil requires a lot of water, but the difficulty is temporary, way more than difficult, the future is good. At present, Yulin in the field of coal chemical industry, coal and other resources into dropping about 400 billion funds, plans to 2020, coal oil production capacity will reach 1600 million tons, to the end of 13th Five-Year, the coal in situ conversion rate reached 50\% .

The Means is to Develop a New Industry. Yulin should vigorously develop new energy industry in Yulin, mainly wind power, photovoltaic, coal-bed methane, shale gas, biomass energy and other resources, the scenery is located in the forefront of the province, mostly concentrated in Yulin and Yuyang. Ding bian-jingbian should also vigorously develop new material industry and manufacturing industry. The main rotor of Yulin new material industry of Shaanxi nonferrous aluminum ingots and salt the 2014 crude salt, aluminum ingot production reached 600 thousand tons, crude salt production reached 1 million 300 thousand tons, but the sale of raw material, low added value, should be the focus of future to the downstream industry chain extension.

Speed up the Adjustment of Industrial Structure. Yulin must optimize and adjust the industrial structure, we should vigorously develop modern agriculture. In northern Yulin along the Great Wall beach wind and focus on the development of high quality forage, feeding livestock; sericulture along the eastern and Southern Yellow Mountain area above 15 degrees steep slope area focus on the development of red dates, and small fruit industry; potato, focus on the development of Western oil, buckwheat and vegetable industry small grains, gentle slope zone; focus on the 
development of southern fruit, red dates, Astragalus and other industries; the development of agricultural and sideline products processing industry in the middle of the 210 national highway. Secondly, develop the third industry. The third industry is the main channel of the employment of the people, and is also an important support stage. Finally, vigorously develop the non-public economy. The development of the private economy, not only to adhere to the equality of rights, equality of opportunity, equal rules, but also in the policy, financing, land and other aspects to give appropriate tilt.

To Enhance the Scientific and Technological Innovation Ability. The innovation of science and technology and a number of enterprises and enterprises in Yulin economy is disproportionate, as small volume, low investment, less mechanism, index and the lagging of the overall weakness, lack of technological innovation, energy is not enough. To do: first, enhance the competitive power, enterprises play the main body of technological innovation the role of technology innovation, high-tech means high risk and high return, enterprises often have a "not to engage in technological innovation will die, technological innovation is dead" mentality. So to stimulate the technological innovation through a variety of ways in power; second, to create a new environment, to play the role of government support to the government. To provide quality and efficient services to the public, the technological innovation of enterprises have a good external environment. Through the government tax relief, to provide land, capital and other factors of production enterprise development necessary policy support on the basis. Yulin energy and chemical industries technology, science and technology research and development center and a number of laboratory construction.

\section{References}

[1] Wei Jundong. "Yulin is the economic development of backward areas that" fast thinking [N]. Yulin daily, 2014-5-27

[2] Wang three. Steady growth should be placed first, [J]. Shanghai economy, 2012 (4):10-11

[3] Wei Jie, Shi Shujie. Focus on the steady growth of the economy should be explored where [J]. economic problems, 2012 (9):1-9

[4] Tong ling, Jin Zhaohuai. Reflections and Countermeasures on the scientific development of private economy [J]. exploration of economic issues, 2012 (4):23-27

[5] Li Jizu, Wei Xiaoxin. [J]. study on coal resource type city development and Countermeasures of Coal Economic Research under the new economic norm, 2014 (11): 71-72.

[6] Li Dejiang etc. Analysis of the Improvement of Enterprises' Competitiveness in Resources-based Cities (Regions) in Hei Longjiang Province [J]. Business Research, 2014 (22)

[7] Ouyang Yanrong. Cultivation of Sustainable Competitiveness of Resource-based Cities- Case Study of Datong, Shanxi Province [J] Resource Development and Market, 2012 (22):143 -146

[8] Zheng Chenghua. A Study of Countermeasures of Energy's Sustainable Development and Utilization in Yulin [ J ]. Market Modernization, 2013 (1) 